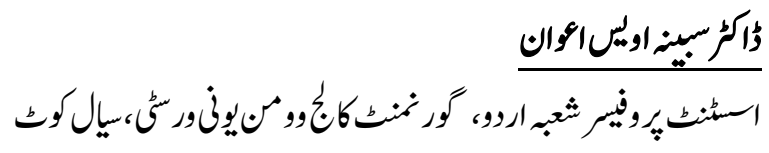

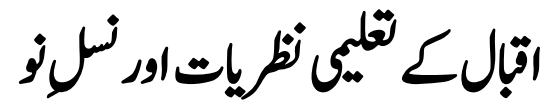

Dr. Sabina Awais

Assistant Professor, Govt. College Women University Sialkot.

\title{
Iqbal's Educational Views and New Generation
}

Iqbal was a philosophical poet, writer, researcher and educationist. He occupies the position of a bright guiding star, a sparking light house and a monument in our literary history. Iqbal's thoughts have left a deep impression on the recent national history. He was also the economist and educationist. He wanted to introduce a separate and an Islamic educational system. The concept of ontology, epistemology, axiology, ego, women education, teaching methodology, curriculum, and character of teacher and development of young Muslims have been taken covered by Iqbal's thoughts. The effects of these concepts are also prominent in his poetry. The Present day, particularly the Muslims will again have to embrace the responsibility of moral and ethical training through which our aspirations will determine our directions. This article is an effort to study these concepts as well as to evaluate the educational scenarios of Iqbal's era.

Key Words: Philosophical Poet, Islamic Educational System, Women Education, Modern and Ethical Training.

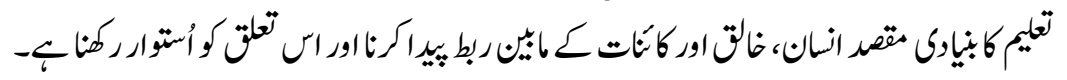

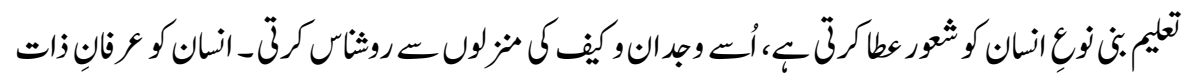

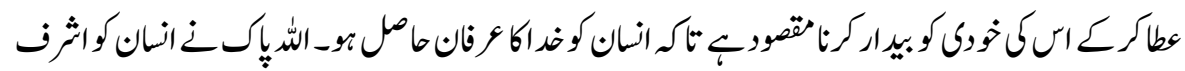

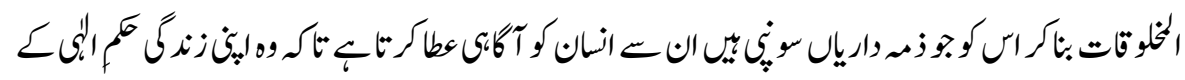

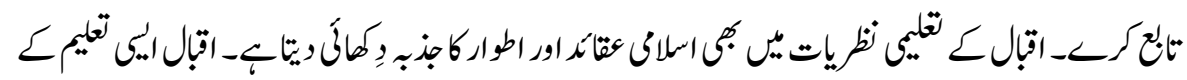

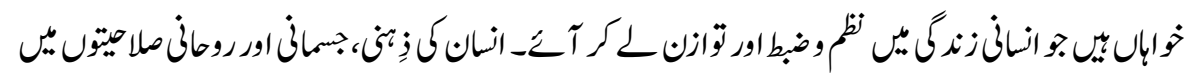

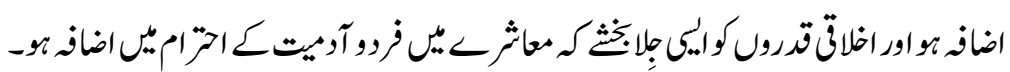




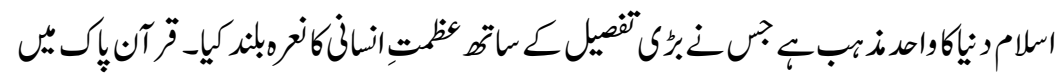

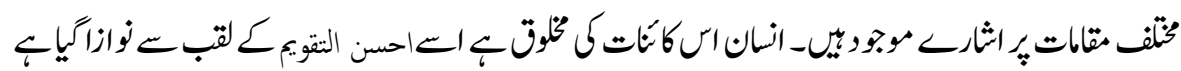

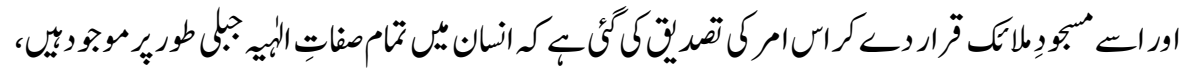

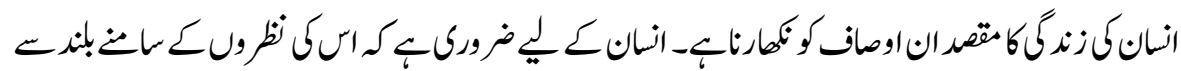

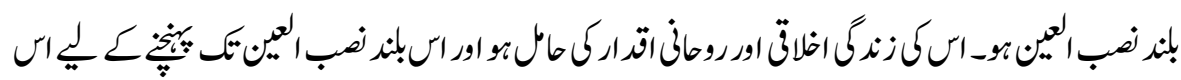

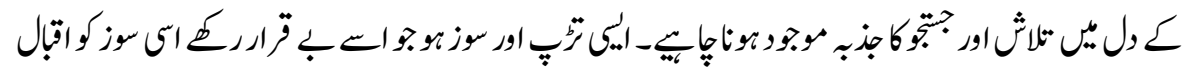

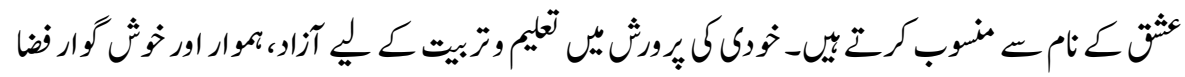

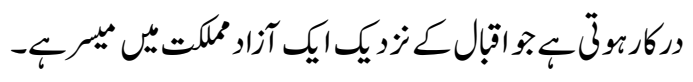

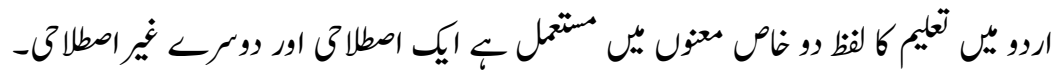

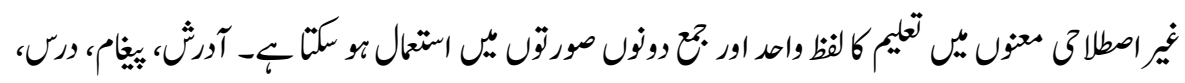

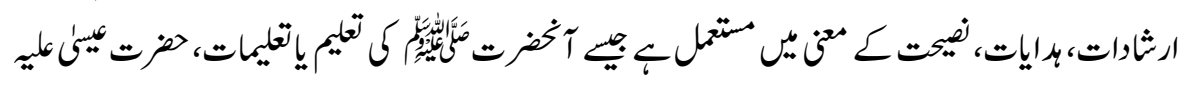

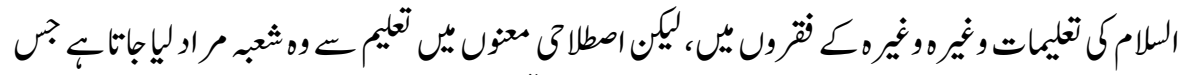

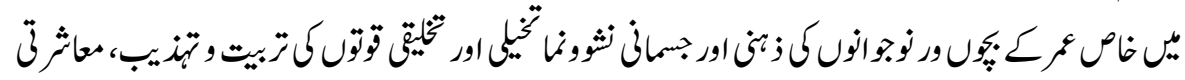

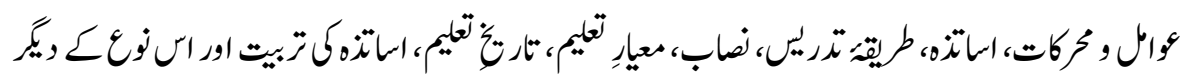

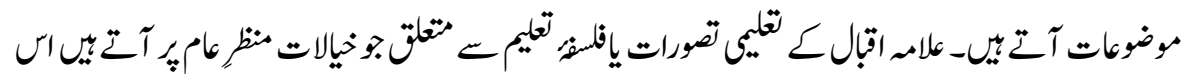

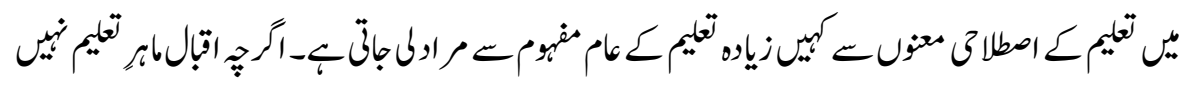

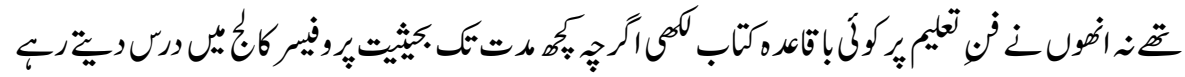

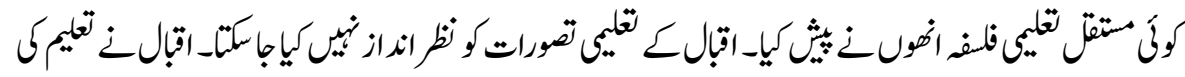

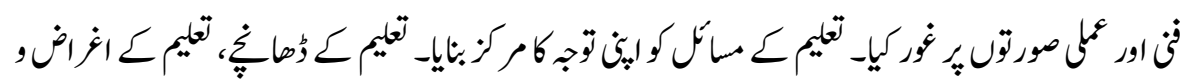

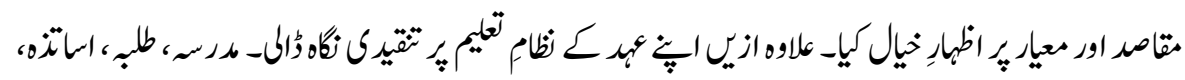

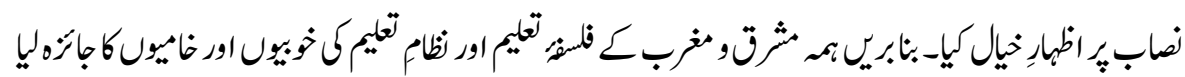

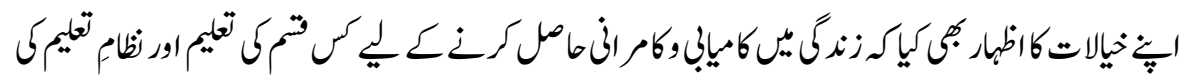

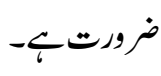




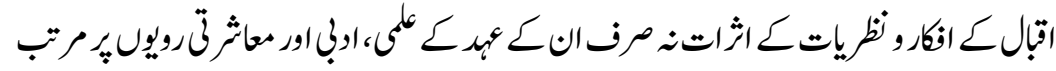

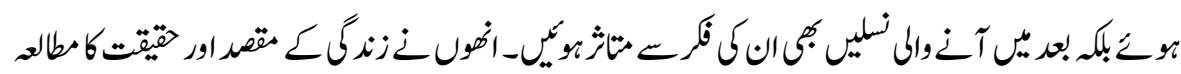

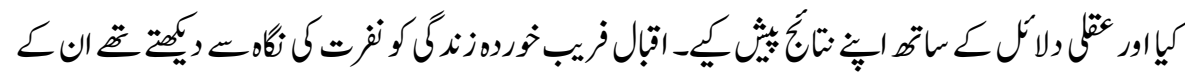

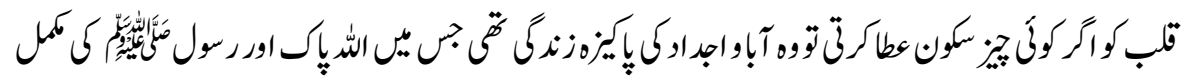

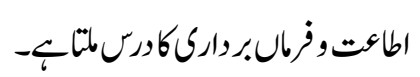

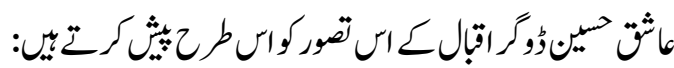

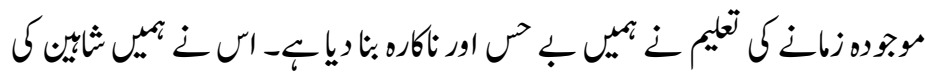

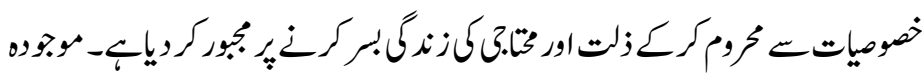

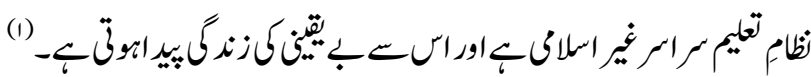

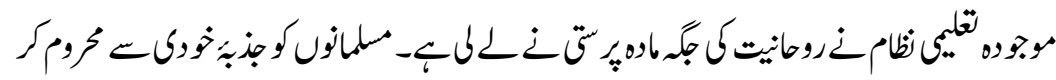

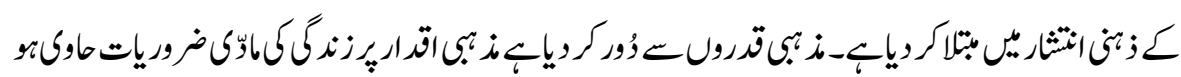

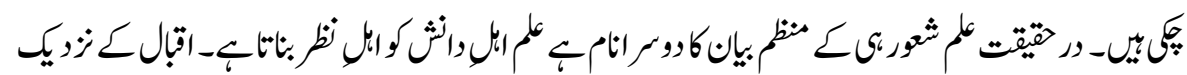

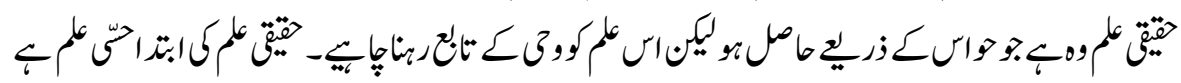

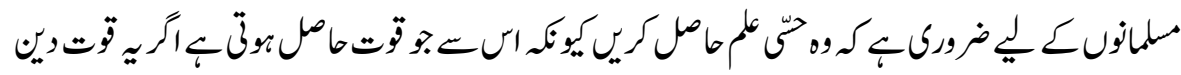

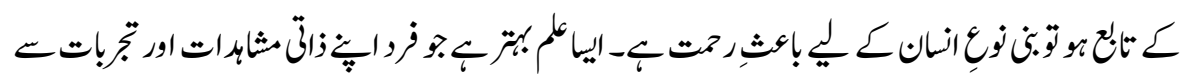

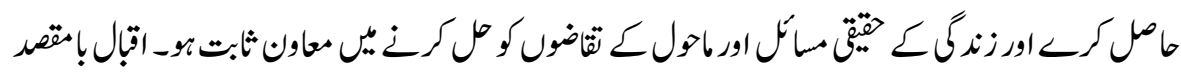

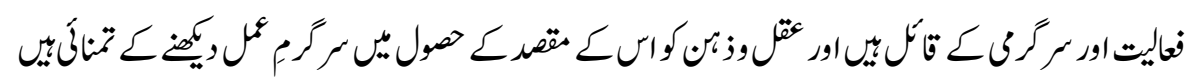

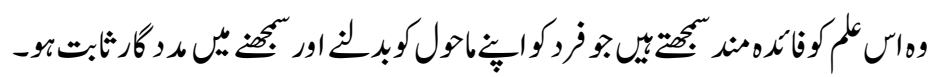

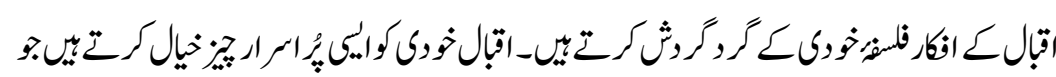

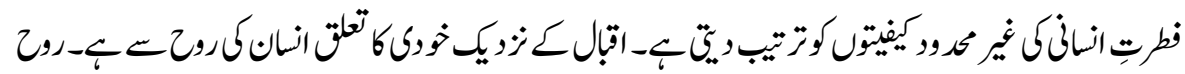

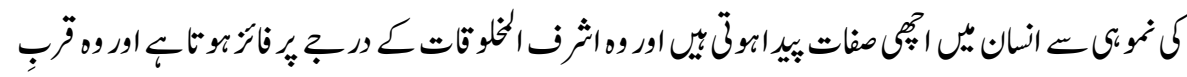

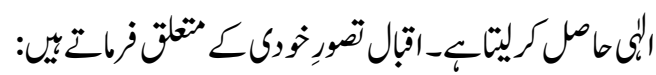




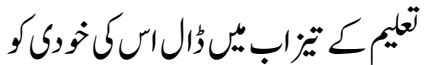

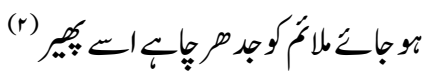

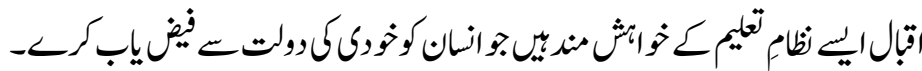

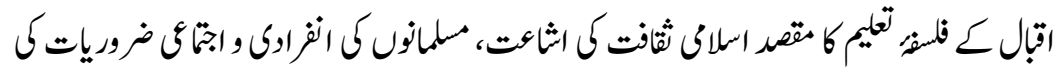

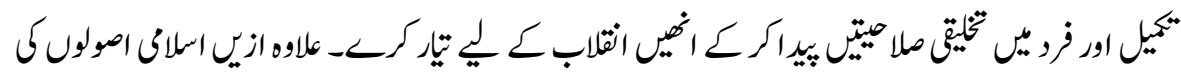

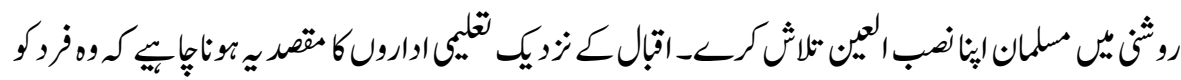

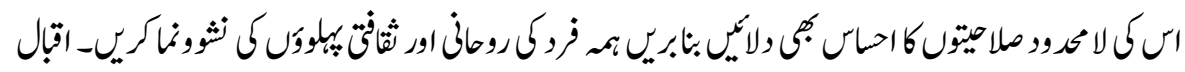

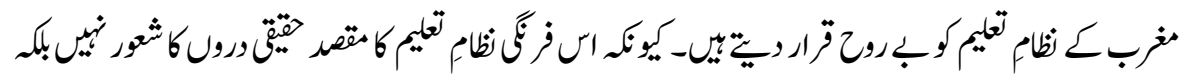

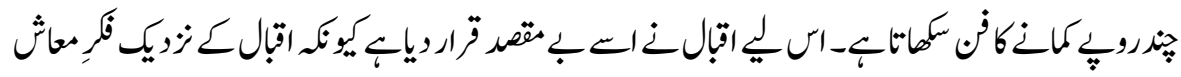

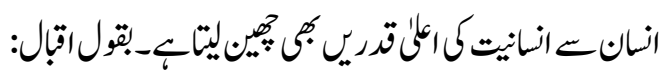

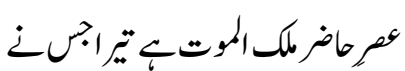

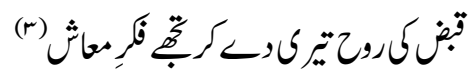

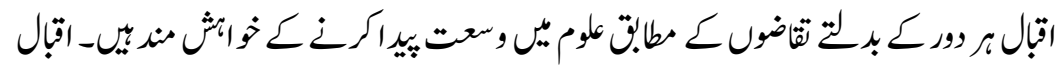

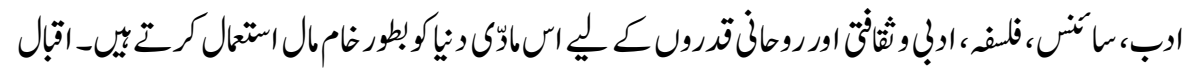

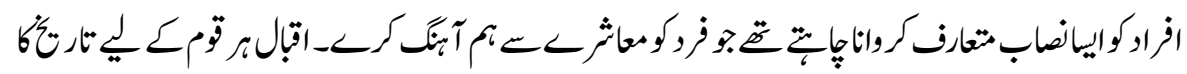

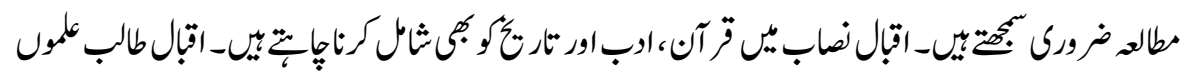

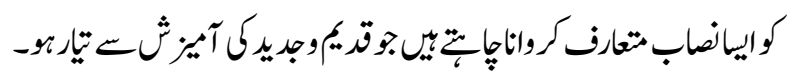

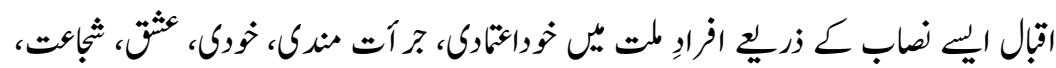

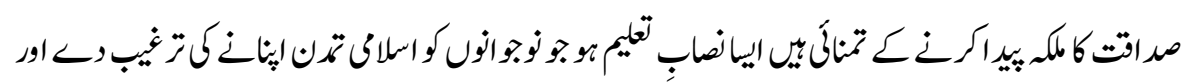

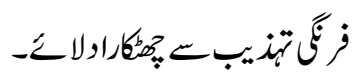

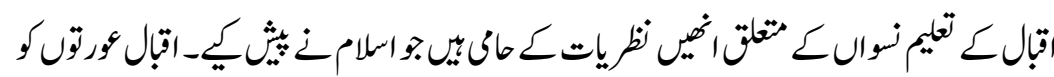

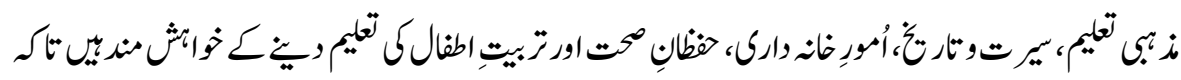

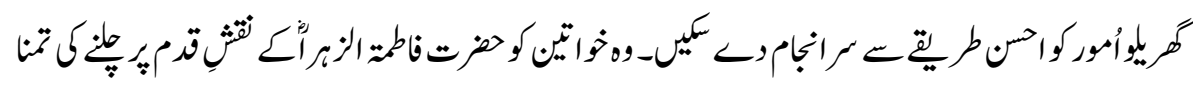




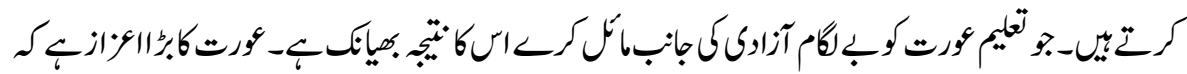

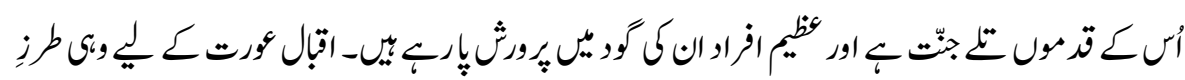

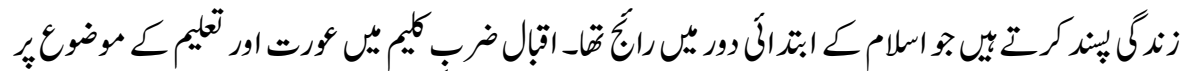

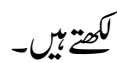

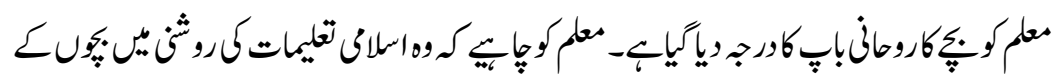

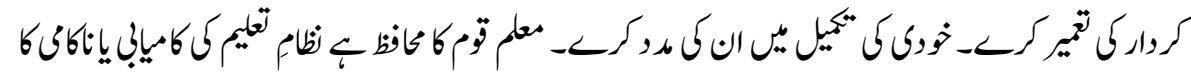

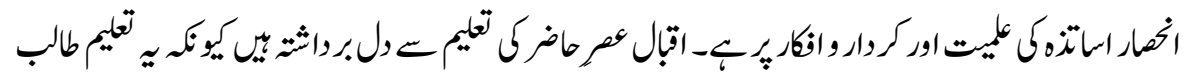

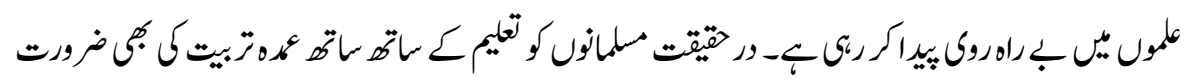

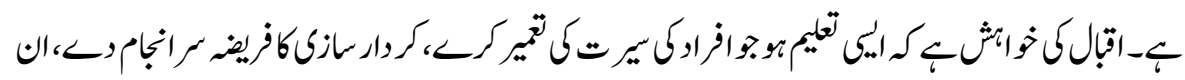

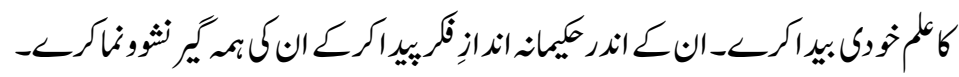

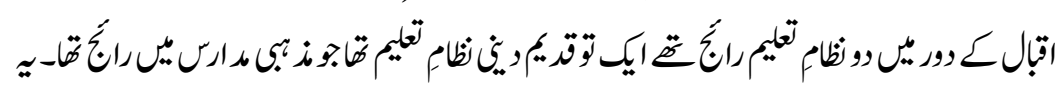

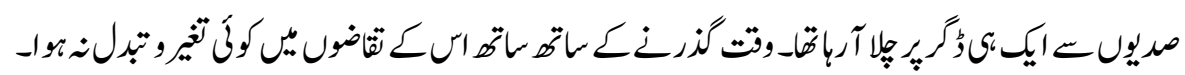

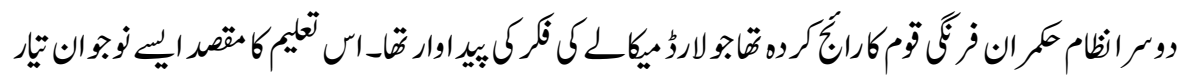

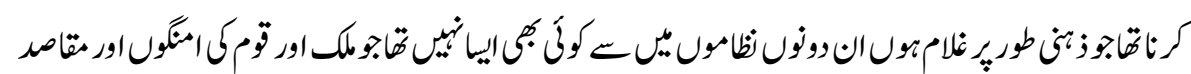

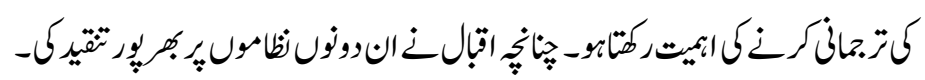

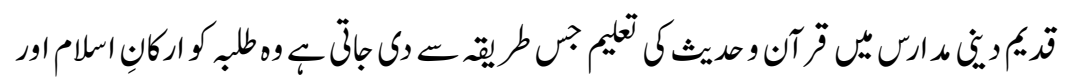

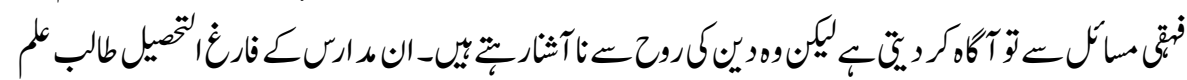

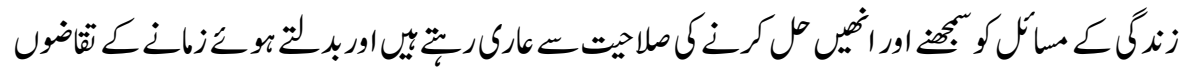

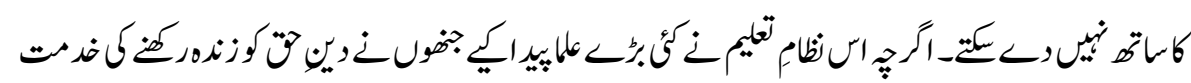

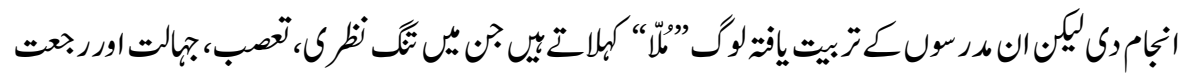

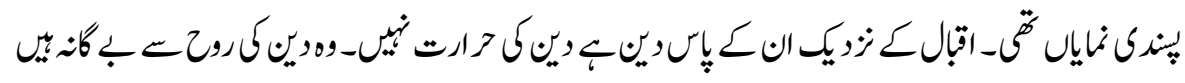

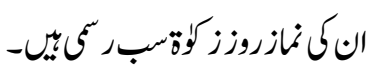

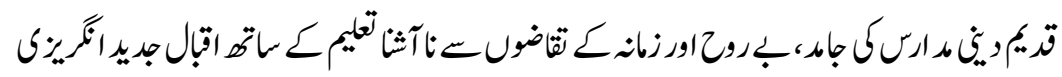




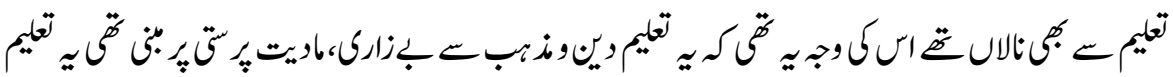

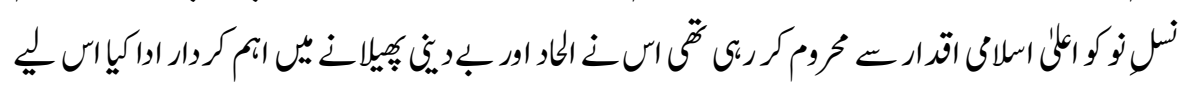

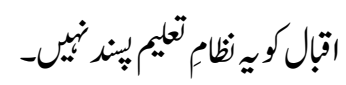

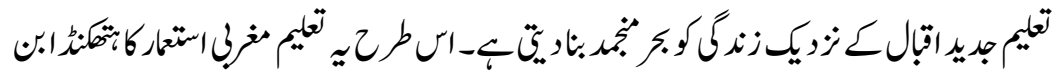

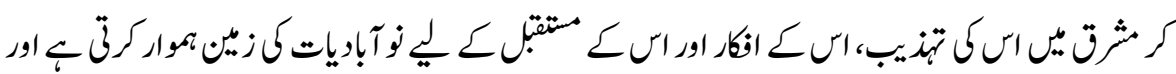

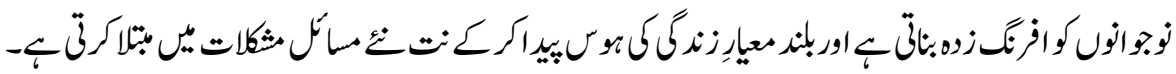

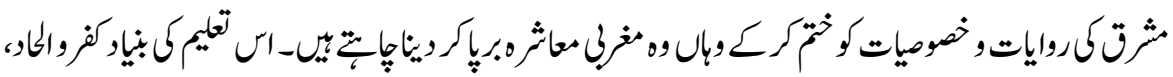

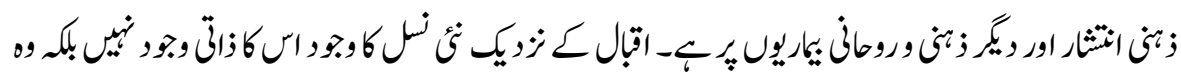

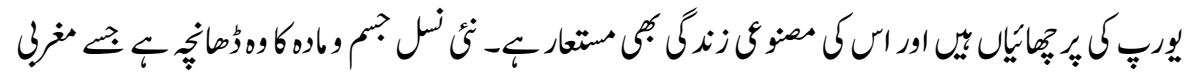

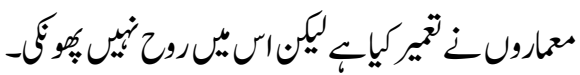

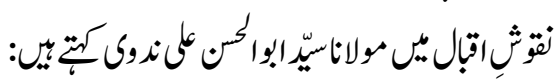

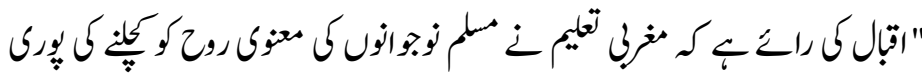

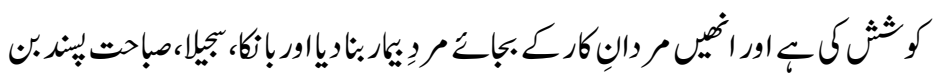

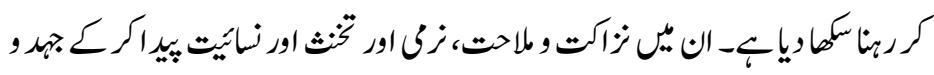

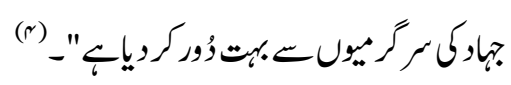

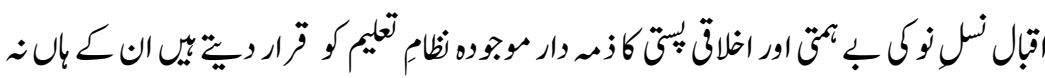

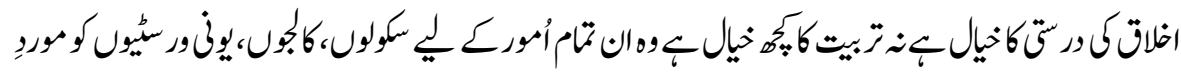

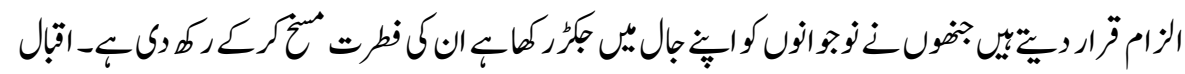

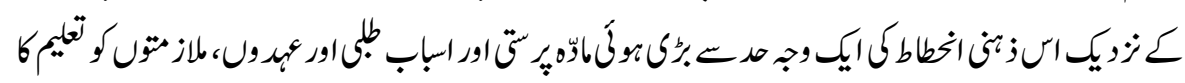

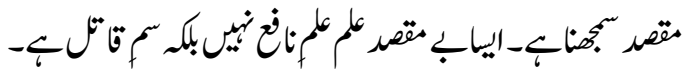

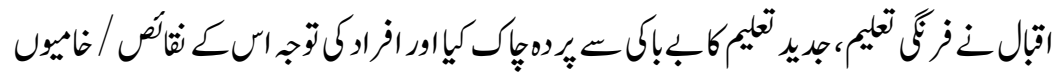

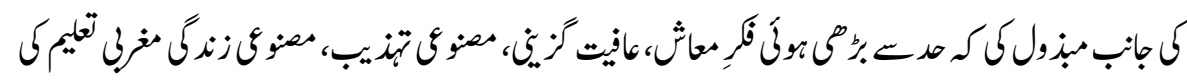

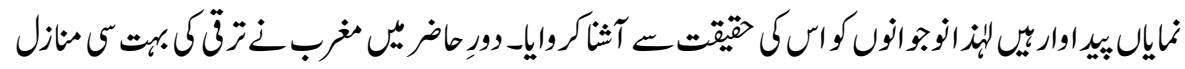




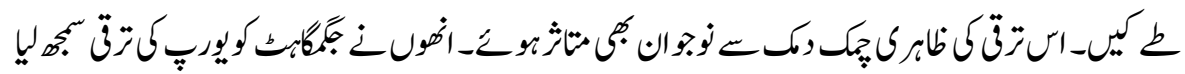

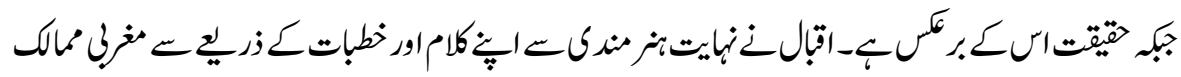

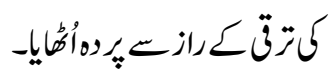

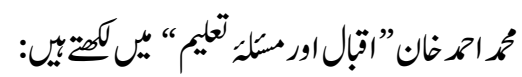

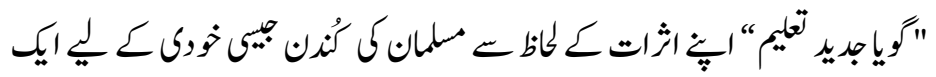

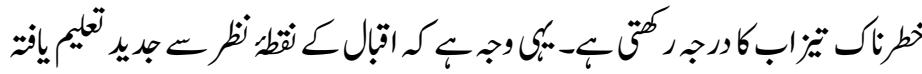

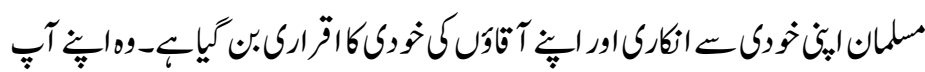

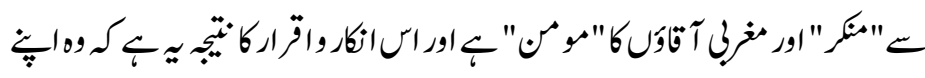

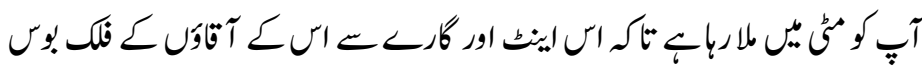

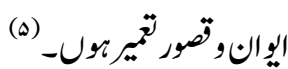
اقبال كنوريك

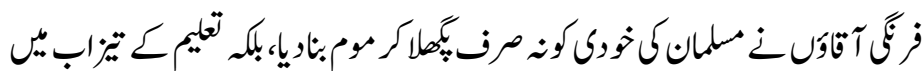

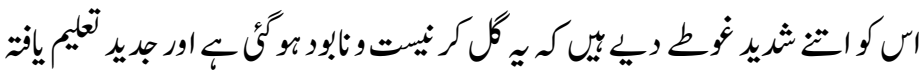

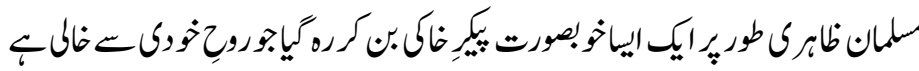

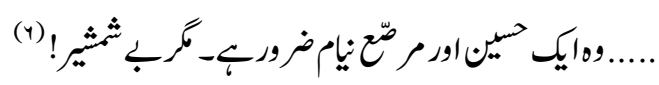

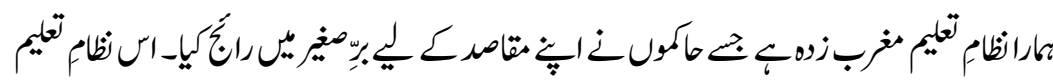

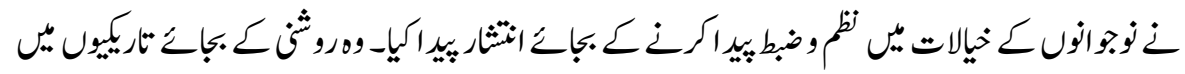

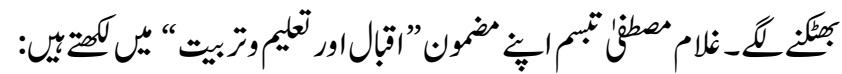

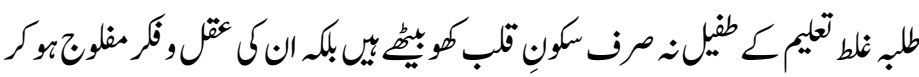

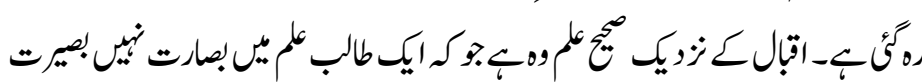

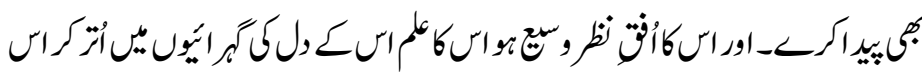

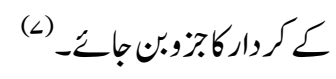

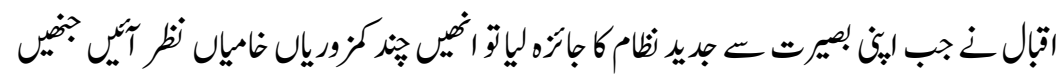




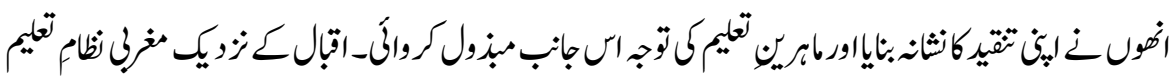

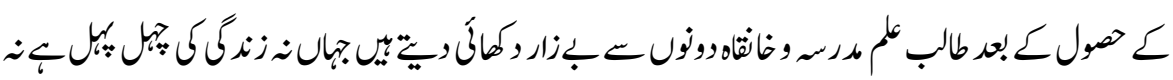

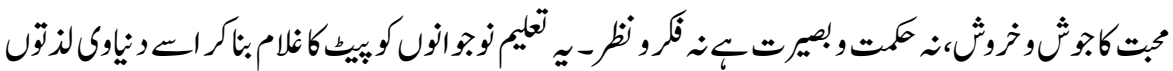

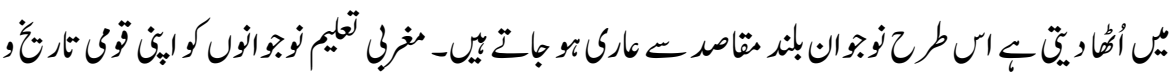

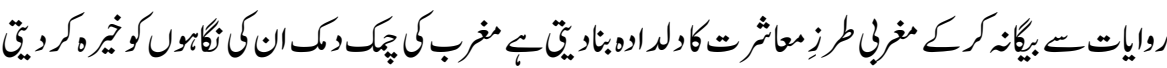

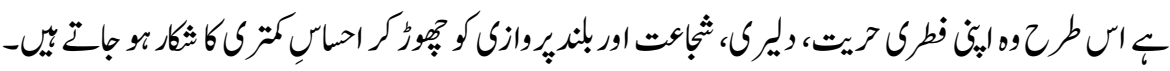

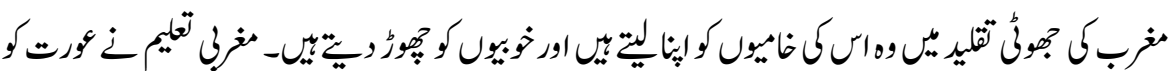

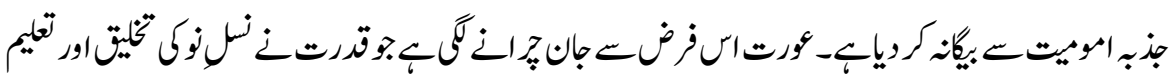

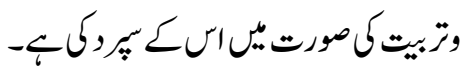

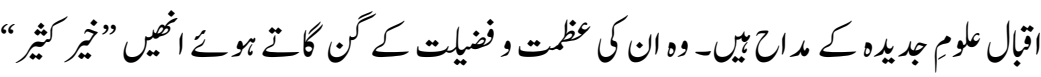

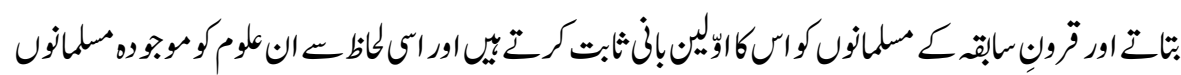

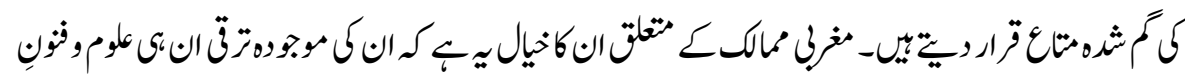

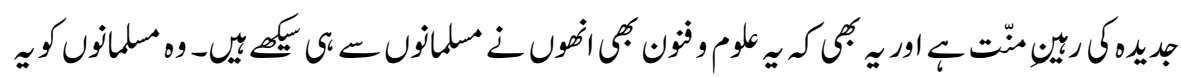

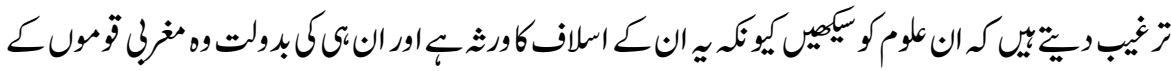

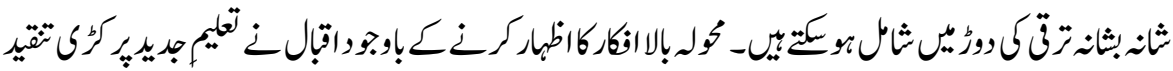

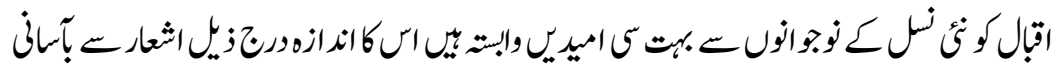

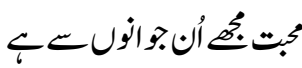

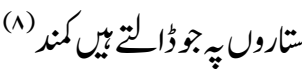

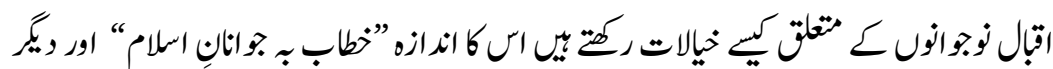

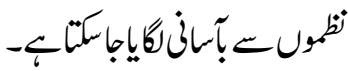

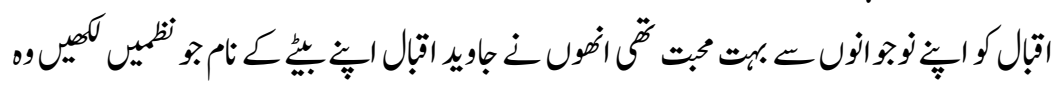




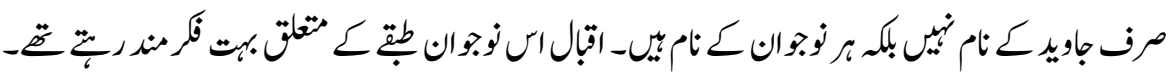

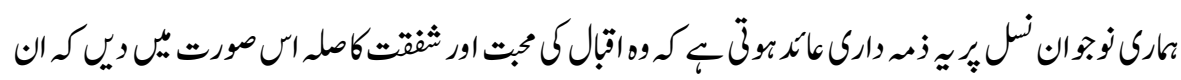

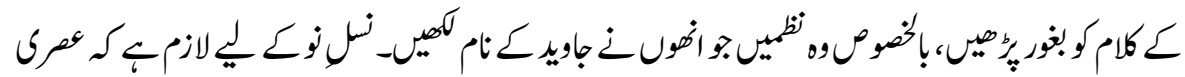

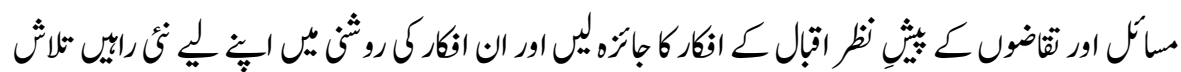

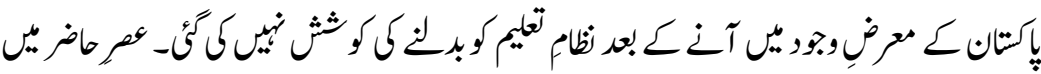

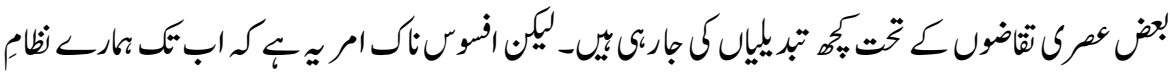

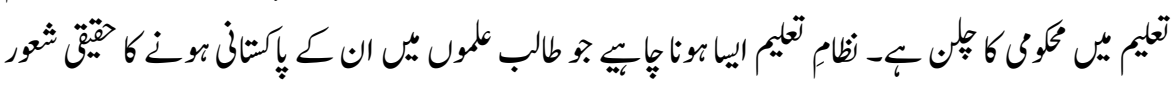

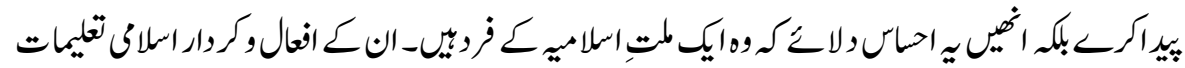

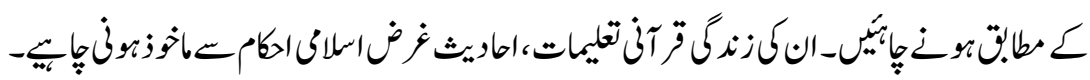

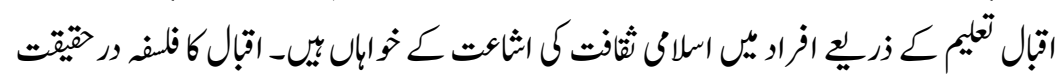

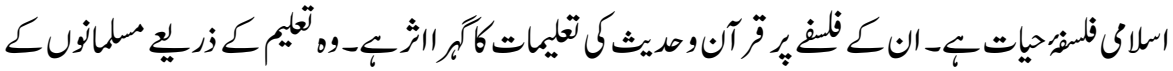

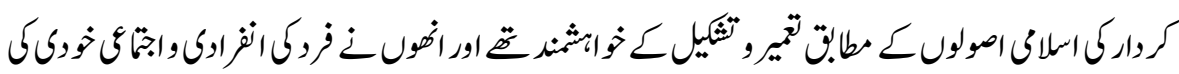

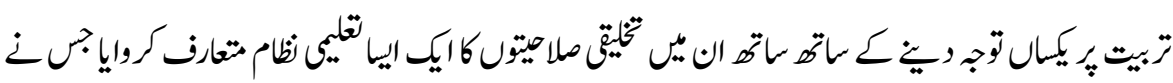

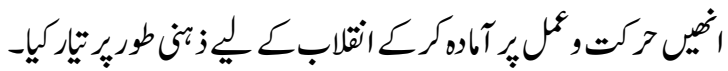

$$
\text { والدجات }
$$

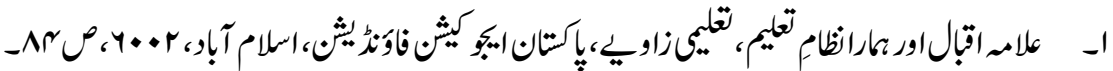

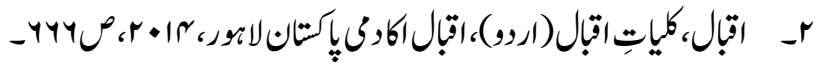
rــ اليضاً، ص994هـ

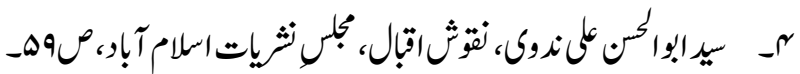

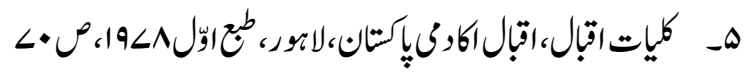




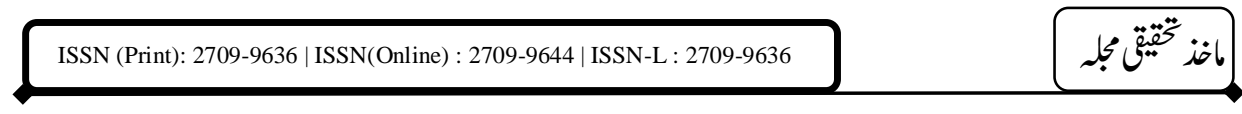

$$
\begin{aligned}
& \text { Y- اليضاً، صr }
\end{aligned}
$$

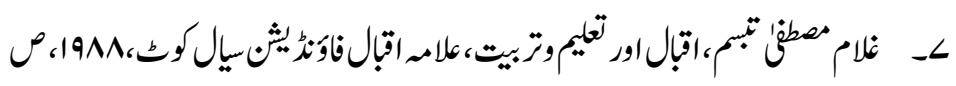

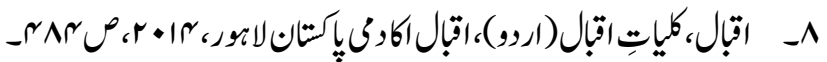

